\section{Melanoma inhibitory antigen}

S. Holdenrieder ${ }^{1}$ und P. Stieber ${ }^{2}$

${ }^{1}$ Institut für Laboratoriumsmedizin, Deutsches Herzzentrum München, Klinik an der Technischen Universität München, München, Deutschland

${ }^{2}$ Institut für Laboratoriumsmedizin, Klinikum der Universität München (LMU), München, Deutschland

\section{$\operatorname{Synonym(e)~MIA~}$}

Englischer Begriff melanoma inhibitory antigen

Definition MIA ist ein $11 \mathrm{kDa}$ schweres, lösliches Protein, das von Melanozyten und Chondrozyten produziert wird.

Struktur MIA besteht aus 131 Aminosäuren und ist lokalisiert auf dem Chromosom 19q13.32.

Molmasse $11 \mathrm{kDa}$.

Synthese - Verteilung - Abbau - Elimination MIA wird von Melanozyten und Chondrozyten produziert und führt im Zellkulturexperiment zu einer schnellen Isolierung und $\mathrm{Ku}$ gelbildung von Melanomzellen, weshalb vermutet wird, dass MIA am Prozess der Metastasierung und/oder der Invasion maligner Melanomzellen beteiligt ist.

Funktion - Pathophysiologie Die klinische Bedeutung der MIA-Bestimmung liegt im Therapiemonitoring und der Rezidiverkennung von malignen Melanomen.
Untersuchungsmaterial-Entnahmebedingungen Serum, Liquor.

Analytik > Enzymimmunoassay (EIA), > Radioimmunoassay (RIA), > Immunradiometrischer Assay (IRMA).

Konventionelle Einheit $\mathrm{ng} / \mathrm{mL}(\mu \mathrm{g} / \mathrm{L})$.

Referenzbereich - Erwachsene $97 \%$-Perzentile 8,8 ng/mL (methodenabhängig).

Interpretation Die meisten MIA-Methoden sind für die Anwendung im Serum ausgetestet. Darüber hinaus kann MIA auch in anderen Körperflüssigkeiten bestimmt werden.

MIA weist eine hohe Tumorspezifität für das maligne Melanom auf. Bei anderen malignen Tumoren wurden nur vereinzelt gering gradige Erhöhungen von MIA im Serum beobachtet. Ebenso verursachen viele differenzialdiagnostisch relevante benigne Erkrankungen keine oder nur gering erhöhte MIA-Konzentrationen. Ein eindeutiger Vorteil gegenüber S100 konnte bisher nicht gezeigt werden; allerdings ist insbesondere bei Melanompatienten mit unauffälliger S100-Konzentration im Serum eine Kombination mit MIA zur Verlaufsbeobachtung sinnvoll.

Diagnostische Wertigkeit Malignes Melanom: Therapiekontrolle und Nachsorge (mit S100), Prognose.

\section{Literatur}

Diamandis E, Fritsche HA, Lilja H et al (2002) Tumor markers. Physiology, pathobiology, technology, and clinical applications, 1. Aufl. AACC Press, Washington, DC 